\title{
Analysis of bromophenols in various aqueous samples using solid phase extraction followed by HPLC-MS/MS
}

\author{
Xiyuan Chi ${ }^{\mathrm{a}, \mathrm{b}}$, Jiyan Liu ${ }^{\mathrm{a}, \mathrm{c}, *}$, Miao Yu ${ }^{\mathrm{a}, \mathrm{c}}$, Zhouqing Xie ${ }^{\mathrm{b}}$, Guibin Jiang ${ }^{\mathrm{a}, \mathrm{c}}$ \\ a State Key Laboratory of Environmental Chemistry and Ecotoxicology, Research Center for Eco-Environmental Sciences, Chinese Academy of Sciences, P.O. \\ Box 2871, Beijing 100085, China \\ b Institute of Polar Environment, School of Earth and Space Sciences, University of Science and Technology of China, Hefei, Anhui 230026, China \\ ${ }^{c}$ College of Resources and Environment, University of Chinese Academy of Sciences, Beijing 100049, China
}

\section{A R T I C L E I N F O}

\section{Keywords:}

Bromophenols

Solid phase extraction

LC-MS/MS

Aqueous samples

\begin{abstract}
A B S T R A C T
A reliable and effective method for simultaneous analysis of trace amount of bromophenols (BPs) in various aqueous samples was developed in this study. The aqueous samples must be acidified after sampling to prevent the fast degradation of bromophenols. Solid-phase extraction was chosen to extract and purify the water samples. High performance liquid chromatography coupled with tandem mass spectrometry with an electrospray ionization source (HPLC-ESI-MS/MS) was used for following identification and quantification. Under the optimized condition, fourteen out of fifteen target brominated phenols were successfully separated and detected with the exception of 2,6-bromophenol (2,6-BP) whose response was too low to be quantified by the MS detector. The method was validated by spiking river water and seawater samples with different concentrations of BPs, and the qualified spiking recoveries (64-100\%) and precisions (0.4-11\% RSD) were obtained. The method detection limits were $0.1-13.9 \mathrm{ng} / \mathrm{L}$ and $0.1-21.9 \mathrm{ng} / \mathrm{L}$ for $0.1 \mathrm{~L}$ of river water and seawater samples, respectively, showing the influences from the sample matrix. The proposed method was successfully applied to the analysis of bromophenol contamination in real water samples, and six bromophenols were identified with a wide concentrations ranging from $\mathrm{ng} / \mathrm{L}$ to $\mu \mathrm{g} / \mathrm{L}$.
\end{abstract}

\section{Introduction}

Brominated phenols (BPs) have high $\mathrm{K}_{\mathrm{ow}}$, high lipophilicity, and even relatively high water solubility. Among them, 2,4,6-tribromophenol (2,4,6-TBP), 2,4-dibromophenol (2,4-DBP), and pentabromophenol (PBP) are increasingly used as a group of novel brominated flame retardants (BFRs) in epoxy and phenolic resins, as replacements for the banned traditional formulations, such as Penta- and Octa- BDEs which were the most widely used and concerned polybrominated diphenyl ethers (PBDEs) [1,2]. 2,4,6-TBP is also employed as intermediates during chemicals synthesis as well as antifungal agents for wood treatment [3]. 2,4,6-TBP is considered as a high production volume chemical by EU, U.S. and Japan with the annual production up to thousands of tons [1]. Furthermore, some traditional BFRs such as tetrabromobisphenol A (TBBPA), PDEDs, and their derivatives all contain BP-like moieties structure. Therefore, BPs may also be degradation products of tetrabromobisphenol A (TBBPA), PBDEs, and other primary BFRs through the photo-transformation under UV irradiation [4], the thermal degradation [5,6], and the biological metabolism process $[7,8]$. 4-BP, 2,4-BP, 2,6-BP and 2,4,6-BP, as the natural products of marine organisms such as algae and polychaetes $[9,10]$, were also found in sea water [11], invertebrates [12], fish and marine mammals $[13,14]$. Some BPs have been found to exhibit adverse health effects, like endocrine disruption and neurotoxicity to organisms [15-18].

Originating from anthropogenic and/or natural sources, 2,4,6-TBP, 2,4-DBP were determined in water and aerosol samples [19,20], soils [21], as well as sewage sludge [22], even in human blood and milk $[23,24]$. Some reports indicated that 2,4,5-TBP, 2,4-DBP and 2,4,6TBP found in the blood of mice and human $[8,25]$ and in polar bear tissues [14] may be formed via metabolic conversion of OH-PBDEs and PBDEs. Recently, Lin et al. [26] have found that OH-PBDEs could form naturally from simple BPs including 2,4-DBP and 2,4,6-TBP with the catalysis of bromoperoxidase. These complex transformation pathways are of particular concern, and could alter the environmental burdens of BPs and other relevant contaminants. Therefore, well understanding on various BPs in the environment can help not only study the environmental and health risk of BPs themselves, but also learn the

* Corresponding author at: State Key Laboratory of Environmental Chemistry and Ecotoxicology, Research Center for Eco-Environmental Sciences, Chinese Academy of Sciences, P.O. Box 2871, Beijing 100085, China.

E-mail address: liujy@rcees.ac.cn (J. Liu). 
environmental processes of other widely concerned compounds such as TBBPA and OH-PBDEs. For the complex origins, diverse transport routes, and high toxicities, it is necessary to develop a proper analytical method to study the occurrence, distribution and fates of BPs in the environment.

Gas chromatography-mass spectrometry (GC/MS) [19,21,27,28] and liquid chromatography coupled with tandem mass spectrometry (LC-MS/MS) $[29,30]$ have previously been used to determine the concentrations of 2,4-DBP, 2,4,6-TBP and PBP. These limited reports on BPs were the appendages of the studies on TBBPA and other phenolic compounds and only focused on three to four BP species. It could not depict all potential BPs in the environment. The relatively high MDLs of these "subordinate" BPs, such as the PBP with MDL up to 46 and $106 \mathrm{ng} / \mathrm{L}[27,28]$, made the methods inappropriate to determine the trace levels of BPs in environmental aqueous samples. To our knowledge, there is only one recent report which specially studied BPs in human urine using LLE-SPE-GC/MS method [31]. However, the method detection limit of $1.8-22.9 \mathrm{ng} / \mathrm{L}$ and recovery of $36-152 \%$ for BPs is not satisfactory enough, especially for the analysis of pollutants at environmental low levels. Thus, a robust analytical method is still urgently needed.

The aim of this work is to develop an effective and reliable analytical method to achieve simultaneous identification and quantification of various brominated phenols in water samples using LC-MS/MS. The mass spectrometer equipped with an electrospray ionization source was operated in negative-ion mode and performed in multiple reaction monitoring (MRM) mode. Pretreatment procedure was established by optimizing SPE method. Different types of real water samples were analyzed to test the reliability of the method. The developed method was evaluated in terms of linearity, sensitivity, spiking recovery and precision.

\section{Experimental section}

\subsection{Chemicals and materials}

Fifteen brominated phenols in toluene, including 3-BP (100 mg/L), 4-BP (100 mg/L), 2,3-BP (100 mg/L), 2,4-BP (100 mg/L), 2,5-BP $(100 \mathrm{mg} / \mathrm{L}), \quad 2,6-\mathrm{BP} \quad(100 \mathrm{mg} / \mathrm{L}), \quad 3,5-\mathrm{BP} \quad(100 \mathrm{mg} / \mathrm{L}), \quad 2,3,4-\mathrm{BP}$ (100 mg/L), 2,4,5-BP (100 mg/L), 2,4,6-BP (100 mg/L), 3,4,5-BP (100 mg/L), 2,3,4,5-BP (100 mg/L), 2,3,4,6-BP (100 mg/L), 2,3,5,6BP $(100 \mathrm{mg} / \mathrm{L})$, and PBP $(100 \mathrm{mg} / \mathrm{L})$, were purchased from AccuStandard (New Haven, CT, USA). Surrogate standard ${ }^{13} \mathrm{C}-3,5-\mathrm{BP}$ $(100 \mathrm{mg} / \mathrm{L})$ and injection internal standard ${ }^{13} \mathrm{C}-2,3,4,6-\mathrm{BP}(100 \mathrm{mg} / \mathrm{L})$ were obtained from Wellington (Guelph, ON, Canada). The purities of these chemicals were $96 \%$ or higher.

Stock solution of each compound was prepared at a concentration of $5 \mathrm{mg} / \mathrm{L}$ by dissolving the standard solution in acetonitrile. Working solutions $(1 \mathrm{mg} / \mathrm{L})$ were prepared weekly by gradually diluting the stock solutions in acetonitrile. Standard mixture solutions in $30 \%$ acetonitrile-water were daily prepared and analyzed for calibration curves. All solutions were stored at $4{ }^{\circ} \mathrm{C}$ in dark until use.

Oasis HLB (150 mg, 6cc), Sep-Pak C18 (500 mg, 6cc), and Sep-Pak C8 (500 mg, 6cc) solid-phase extraction cartridges were purchased from Waters (Milford, MA, USA). HPLC grade methanol and acetonitrile, pesticide grade acetone and ethyl acetate, and all other organic solvents were purchased from J.T. Baker (Phillipsburg, NJ, USA). Ultrapure water $(18.3 \mathrm{M} \Omega \times \mathrm{cm})$ was generated by a Milli-Q system (Millipore, Billerica, MA, USA). Guarantee reagent (GR) hydrochloric acid was obtained from Beijing Chemical Works (Beijing, China).

\subsection{Sample collection and preparation}

River water sample was collected from Qinghe River, Haidian district, Beijing in April 2014. The sampling site was near a domestic sewage outlet. Swimming pool water sample was collected from an indoor swimming pool in Haidian district, Beijing in May 2014. Coastal sea water samples from Bohai Sea were obtained from Binhai district, Tianjin and Shahekou district, Dalian from April to June, 2014. Waste water sample was collected from a chemical plant in Weifang, Shandong province in June, 2014. Water samples were collected in $4 \mathrm{~L}$ amber glass bottles which were pre-cleaned with acetone. After acidified to $\mathrm{pH} 2.5$ with hydrochloric acid on site, samples were transferred back to laboratory instantly and then stored at $4{ }^{\circ} \mathrm{C}$ in dark. All the samples were analyzed as soon as possible. Prior to analysis, the water samples were restored to room temperature, and then filtered through Whatman GF/F glass microfiber filters $(0.7 \mu \mathrm{m}$, Whatman, Maidstone, UK).

\subsection{Extraction and clean-up}

Solid phase extraction was carried out to extract BPs from aqueous samples. The ultrapure water sample $(100 \mathrm{~mL})$, spiked with a mixture of working solutions containing all the target brominated phenols (15 ng for each) and $15 \mathrm{ng}{ }^{13} \mathrm{C}-3,5-\mathrm{BP}$ as recovery surrogate standard, was employed to optimize the performance of the method (three replicates). Under the optimized condition, $100-300 \mathrm{~mL}$ of real water samples were drawn through the Oasis HLB cartridges at a flow rate of $5 \mathrm{~mL} / \mathrm{min}$. The cartridges were firstly conditioned with $7 \mathrm{~mL}$ of methanol and $7 \mathrm{~mL}$ of water successively. After sample loading, $50 \mathrm{~mL}$ of ultrapure water and $5 \mathrm{~mL}$ of ultrapure water-methanol solution $(4: 6, v: v)$ were used to wash the cartridges in sequence to eliminate the hydrochloric acid and the impurities in samples. After the cartridges were vacuum dried for $20 \mathrm{~min}$, the elution was performed with $6 \mathrm{~mL}$ of methanol. The eluents were evaporated to dryness under a gentle stream of nitrogen at $50^{\circ} \mathrm{C}$, and then re-dissolved in ultrapure water-acetonitrile solution $(7: 3, v: v)$. Fifteen nanograms of ${ }^{13} \mathrm{C}-2,3,4,6-$ $\mathrm{BP}$ was added into the sample vial as injection internal standard, and the final volume of the sample was adjusted to $1 \mathrm{~mL}$.

\subsection{LC-MS/MS analysis}

The analysis of target BPs was performed using an UltiMate 3000 BioRS ultra high performance liquid chromatograph (Thermo Fisher Scientific Inc., Waltham, MA, USA) coupled with Triple Quad 5500 MS/MS system (AB SCIEX Inc., Framingham, MA, USA). An Accucore C18 column ( $100 \mathrm{~mm} \times 2.1 \mathrm{~mm}$ i.d., $2.6 \mu \mathrm{m}$ particle size, Thermo Fisher Scientific Inc., Waltham, MA, USA) was chosen to separate BPs with the column temperature maintaining at $40{ }^{\circ} \mathrm{C}$. The gradient mobile phase started from $30 \%$ methanol $(v / v)$ to $45 \%$ in the first $5 \mathrm{~min}$, then increased to $70 \%$ within $15 \mathrm{~min}$, and finally to $80 \%$ in $5 \mathrm{~min}$. After the program, the composition of the mobile phase return to initial state and held for $8 \mathrm{~min}$ to re-equilibrate. The total running for one injection lasted for $33 \mathrm{~min}$ with a constant flow rate of $0.4 \mathrm{~mL} / \mathrm{min}$. The injection volume was $5 \mu \mathrm{L}$.

The mass spectrometer equipped with an electrospray ionization source was operated in negative-ion mode. Details on the Turbo $\mathrm{V}^{\mathrm{TM}}$ ion sources settings were: temperature $500{ }^{\circ} \mathrm{C}$, curtain gas $40 \mathrm{psi}$, spray voltage $-4500 \mathrm{v}$, nebulizer gas $50 \mathrm{psi}$, auxiliary heating gas $50 \mathrm{psi}$. [M$\mathrm{H}^{-}$was parent ion for each BP analyte, and m/z 79 and 81 were the daughter ions. The determination of 15 targeted BPs was conducted in multiple reaction monitoring (MRM) mode. The parameters optimized to achieve maximum selectivity are shown in Table 1.

\subsection{Quality assurance/quality control}

The BPs were identified according to the performance criteria for analytical methods by the commission of the European Communities [32]. In short, the relative retention time of the analytes should match that of standards at a tolerance of $2 \%$ for liquid chromatography. The calibration curves were constructed using standards with concentrations of $0.1,0.2,0.5,1,2,5,10,20$ and $50 \mu \mathrm{g} / \mathrm{L}$ for each analyte. The 
Table 1

MRM parameters for qualitative and quantitative determination of BPs.

\begin{tabular}{|c|c|c|c|c|c|c|}
\hline \multirow[t]{2}{*}{ Compounds } & \multirow[t]{2}{*}{ Formula } & \multirow[t]{2}{*}{ Parent ions $(\mathrm{m} / \mathrm{z})$} & \multicolumn{2}{|c|}{ Daughter ions $(\mathrm{m} / \mathrm{z})$} & \multirow[t]{2}{*}{ Declustering potential (v) } & \multirow[t]{2}{*}{ Collision energy (v) } \\
\hline & & & Quantitative ion & Qualitative ion & & \\
\hline \multirow[t]{2}{*}{ 3-BP } & \multirow[t]{2}{*}{$\mathrm{C}_{6} \mathrm{H}_{5} \mathrm{BrO}$} & 170.8 & 78.8 & & -85 & -22 \\
\hline & & 172.8 & & 80.8 & & \\
\hline \multirow[t]{2}{*}{ 4-BP } & \multirow[t]{2}{*}{$\mathrm{C}_{6} \mathrm{H}_{5} \mathrm{BrO}$} & 170.8 & 78.8 & & -85 & -22 \\
\hline & & 172.8 & & 80.8 & & \\
\hline $2,3-\mathrm{BP}$ & $\mathrm{C}_{6} \mathrm{H}_{4} \mathrm{Br}_{2} \mathrm{O}$ & 250.8 & 78.8 & 80.8 & -110 & -30 \\
\hline 2,4-BP & $\mathrm{C}_{6} \mathrm{H}_{4} \mathrm{Br}_{2} \mathrm{O}$ & 250.8 & 78.8 & 80.8 & -110 & -30 \\
\hline $2,5-\mathrm{BP}$ & $\mathrm{C}_{6} \mathrm{H}_{4} \mathrm{Br}_{2} \mathrm{O}$ & 250.8 & 78.8 & 80.8 & -110 & -30 \\
\hline $2,6-\mathrm{BP}^{\mathrm{a}}$ & $\mathrm{C}_{6} \mathrm{H}_{4} \mathrm{Br}_{2} \mathrm{O}$ & 250.8 & 78.8 & 80.8 & -110 & -30 \\
\hline $3,5-\mathrm{BP}$ & $\mathrm{C}_{6} \mathrm{H}_{4} \mathrm{Br}_{2} \mathrm{O}$ & 250.8 & 78.8 & 80.8 & -110 & -30 \\
\hline 2,3,4-BP & $\mathrm{C}_{6} \mathrm{H}_{3} \mathrm{Br}_{3} \mathrm{O}$ & 328.8 & 78.8 & 80.8 & -120 & -70 \\
\hline $2,4,5-\mathrm{BP}$ & $\mathrm{C}_{6} \mathrm{H}_{3} \mathrm{Br}_{3} \mathrm{O}$ & 328.8 & 78.8 & 80.8 & -120 & -70 \\
\hline $2,4,6-\mathrm{BP}$ & $\mathrm{C}_{6} \mathrm{H}_{3} \mathrm{Br}_{3} \mathrm{O}$ & 328.8 & 78.8 & 80.8 & -120 & -70 \\
\hline $3,4,5$-BP & $\mathrm{C}_{6} \mathrm{H}_{3} \mathrm{Br}_{3} \mathrm{O}$ & 328.8 & 78.8 & 80.8 & -120 & -70 \\
\hline 2,3,4,5-BP & $\mathrm{C}_{6} \mathrm{H}_{2} \mathrm{Br}_{4} \mathrm{O}$ & 408.6 & 78.8 & 80.8 & -130 & -85 \\
\hline 2,3,4,6-BP & $\mathrm{C}_{6} \mathrm{H}_{2} \mathrm{Br}_{4} \mathrm{O}$ & 408.6 & 78.8 & 80.8 & -130 & -85 \\
\hline 2,3,5,6-BP & $\mathrm{C}_{6} \mathrm{H}_{2} \mathrm{Br}_{4} \mathrm{O}$ & 408.6 & 78.8 & 80.8 & -130 & -85 \\
\hline PBP & $\mathrm{C}_{6} \mathrm{HBr}_{5} \mathrm{O}$ & 488.6 & 78.8 & 80.8 & -130 & -82 \\
\hline${ }^{13} \mathrm{C}-3,5-\mathrm{BP}{ }^{\mathrm{b}}$ & ${ }^{13} \mathrm{C}-\mathrm{C}_{6} \mathrm{H}_{4} \mathrm{Br}_{2} \mathrm{O}$ & 256.8 & 78.8 & 80.8 & -110 & -30 \\
\hline${ }^{13} \mathrm{C}-2,3,4,6-\mathrm{BP}^{\mathrm{b}}$ & ${ }^{13} \mathrm{C}-\mathrm{C}_{6} \mathrm{H}_{2} \mathrm{Br}_{4} \mathrm{O}$ & 414.6 & 78.8 & 80.8 & -130 & -85 \\
\hline
\end{tabular}

a The response of 2,6-BP was too low to be detected.

b Internal standards.

calibration was daily determined to cope with the retention time variations caused by carryover effect. Good linearity with $\mathrm{r}^{2}$ over 0.998 was achieved for all the analytes in range of $0.1-50 \mu \mathrm{g} / \mathrm{L}$. Procedure blanks were added in parallel with every batch of five samples.

On the basis of signal-to-noise ratio of $3(\mathrm{~S} / \mathrm{N}=3)$, the equipment detection limits (EDLs) and method detection limits (MDLs) for all the BPs were $0.03-2.4 \mathrm{pg}$ and $0.1-21.9 \mathrm{ng} / \mathrm{L}$, respectively. The spiking recovery and precision were investigated by spiking standard solutions into sea water samples at concentrations of 100 and $1000 \mathrm{ng} / \mathrm{L}$, and river samples at concentration of $150 \mathrm{ng} / \mathrm{L}$. The recoveries of target analytes ranged from $64 \%$ to $100 \%$. The relative standard deviations (RSD, $\mathrm{n}=3$ ) were less than $11 \%$ for all BPs.

\section{Results and discussion}

Solid phase extraction combined with LC-MS-MS in ESI mode was tested and evaluated regarding the feasibility, rapidness and high throughput of the method. Various parameters affecting the extraction and instrumental detection were optimized in detail as follow.

\subsection{Chromatographic separation of BPs}

The chromatographic separation solves the co-elution of isomeric compounds. Here four LC columns were tested to achieve the best separation, including Syncronis $\mathrm{C}_{18}$ column $(100 \mathrm{~mm} \times 2.1 \mathrm{~mm}$, $1.7 \mu \mathrm{m})$, Accucore $\mathrm{C}_{18}$ column $(100 \mathrm{~mm} \times 2.1 \mathrm{~mm}, 2.6 \mu \mathrm{m})$, Accucore PFP column $(100 \mathrm{~mm} \times 2.1 \mathrm{~mm}, 2.6 \mu \mathrm{m})$, and Acclaim RSLC $120 \mathrm{C}_{18}$ column $(100 \mathrm{~mm} \times 2.1 \mathrm{~mm}, 2.2 \mu \mathrm{m})$, which were all purchased from
Thermo Fisher Scientific. Among them, Accucore $\mathrm{C}_{18}$ column $(100 \mathrm{~mm} \times 2.1 \mathrm{~mm}, 2.6 \mu \mathrm{m})$ gave the best selectivity for majority of the BPs.

Different mobile phases and gradient slopes were tested in order to improve the separation resolution and signal intensity. Compared to the performance from the mobile phase of acetonitrile-water system, the mixture of methanol and water enhanced the signal intensity for most target compounds. Fig. 1 shows the total ion chromatogram (TIC) of 14 bromophenols and the internal standard under the optimized condition, with the exception of 2,6-DBP whose response was too low to be quantified by MS detector. The ionization of 2,6-DBP in the MS detector was very hard due to its molecule structure with two $\mathrm{Br}$ atoms on both sides of $\mathrm{OH}$ substitution. The intensity of 2,6-DBP signal was over two order magnitude lower than that of other BPs and still indiscernible even at a very high injection concentration of $1 \mathrm{mg} / \mathrm{L}$ which was much higher than the environment levels.

\subsection{Pretreatment procedure}

\subsubsection{SPE sorbents}

According to the different hydrophobicities and polarities of BPs [33], SPE cartridges packed by three sorbents (C18, C8, and Oasis HLB) with distinct characteristics were tested to evaluate the extraction efficiency for BPs. Fig. 2 shows the spiking recoveries (DI water) of BPs based on these different SPE cartridges. C8 cartridges provided poor recoveries for 3-BP and 4-BP ( $<51 \%)$. The extraction efficiency of C8 cartridges for the other BPs increased with the increase of bromine atom number on benzene ring, and the good recovery (89\%) of pentabromophenol was obtained. For C18 cartridges, the recoveries 


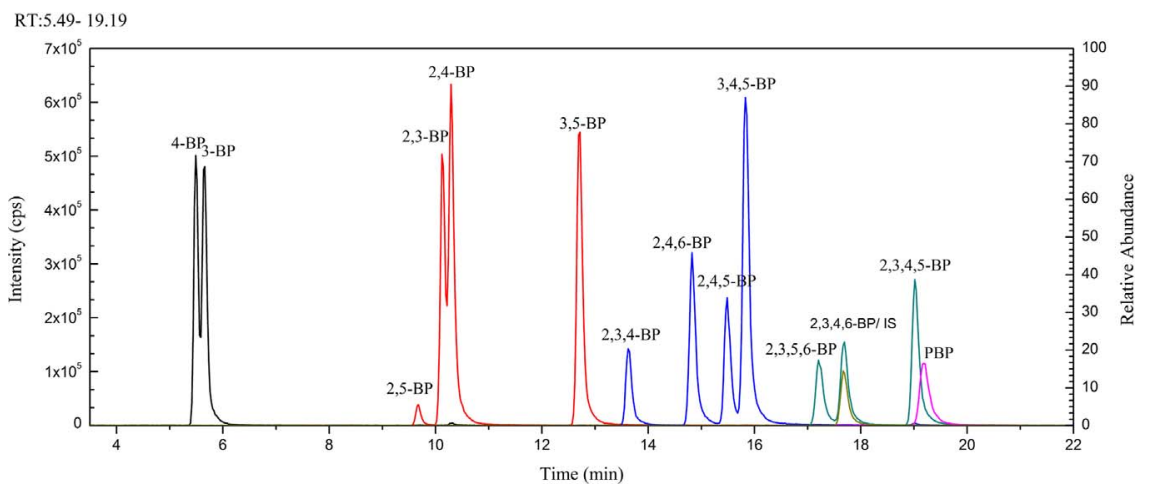

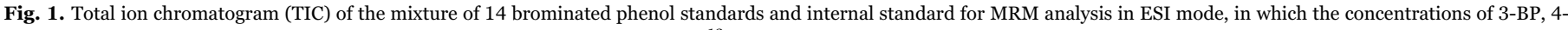

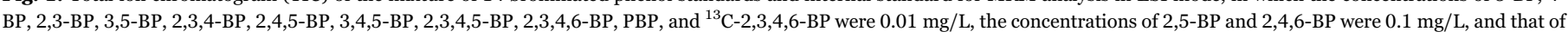
2,4-BP was $0.5 \mathrm{mg} / \mathrm{L}$.

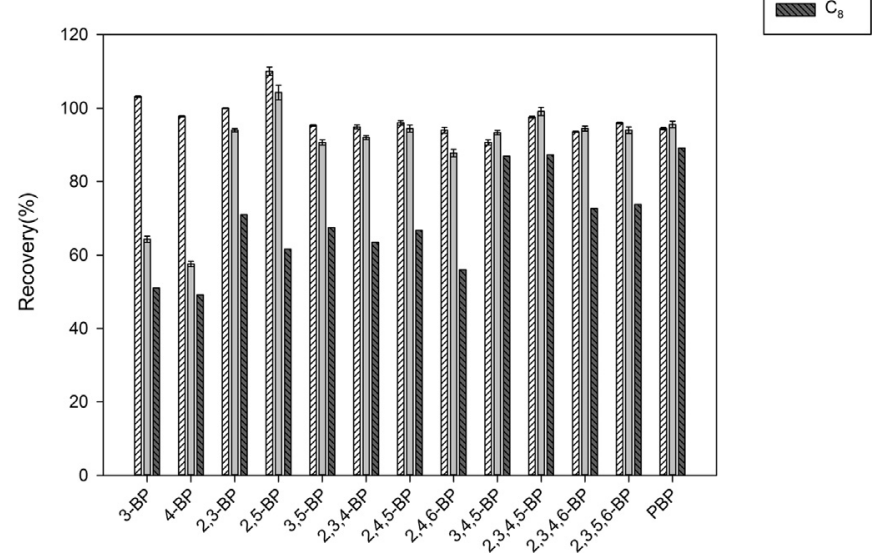

Fig. 2. The spiking recoveries (\%) of the BPs in DI water pretreated with HLB, C18, C8 cartridges with the spiking concentration of $0.015 \mathrm{mg} / \mathrm{L}(\mathrm{n}=3)$.

were improved to $64 \%$ and $58 \%$ for monobromophenols, and good recoveries were achieved for the other BPs (88-104\%). HLB copolymer cartridges displayed best performance with the highest recoveries (91$110 \%)$ and the lowest relative standard deviations (0.7-7\%) for all BPs. The differences in extraction efficiencies on three kinds of SPE columns were directly related to the properties of SPE sorbents and the polarities of BPs. 3-BP and 4-BP are more hydrophilic, and have lower affinities with non-polar silica gel sorbents in comparison with tri-, tetra and pentabromophenols [34]. The HLB is a porous polymeric sorbent with an appropriate ratio of the monomers hydrophilic Nvinylpyrrolidone and lipophilic divinylbenzene, providing better reversed-phase capacity for the retention of polar mono-bromophenol molecules [35]. Similar good extraction efficiencies were obtained by HLB cartridges for chlorophenols, the structural analogues of bromophenols [36-38]. Therefore, HLB cartridge was chosen for the subsequent analysis.

\subsubsection{Elution solvents}

The polarity of elution solvent could affect the recoveries of targeted compounds to a great extent. Methanol [37,39], acetone and ethyl acetate $[40,41]$, which were commonly used for quantitative desorption of phenolic compounds from HLB cartridge, were tested for the elution of BPs. According to Snyder polarity index, the polarities of three elution solvents in an ascending order is ethyl acetate (polar index, $\left.\mathrm{P}^{\prime}=4.3\right)<$ acetone $\left(\mathrm{P}^{\prime}=5.4\right)<$ methanol $\left(\mathrm{P}^{\prime}=6.6\right)[42-44]$.

As shown in Fig. 3, ethyl acetate presents weakest eluting power towards BPs. Very poor spiking recoveries $(<17 \%)$ were obtained for tri-, tetra and pentabromophenols compared with mono- and dibro-

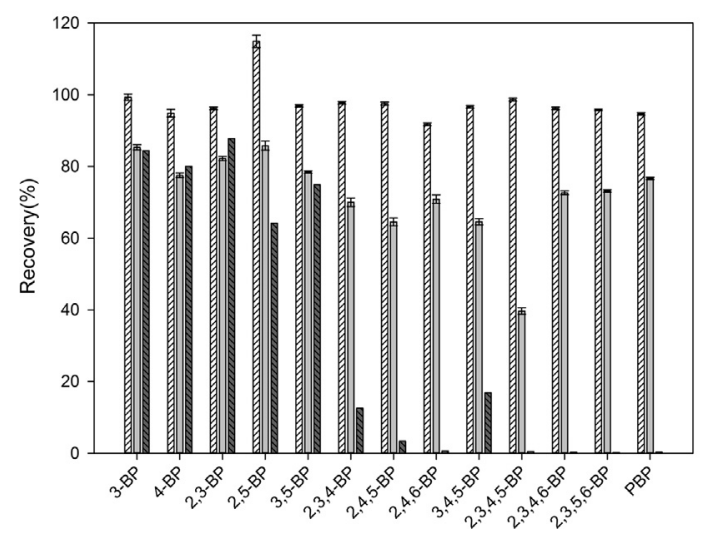

Fig. 3. The spiking recoveries (\%) of the BPs using HLB cartridges after elution with different solvents (the spiking concentration of $0.015 \mathrm{mg} / \mathrm{L}, \mathrm{n}=3$ ).

mophenols (64-88\%). Acetone yielded a little bit better recoveries (40$86 \%$ ) than ethyl acetate for the analytes, owing to its higher polarity. For ethyl acetate and acetone, the recoveries seemed to systematically decrease with the increase of bromine atoms on bromophenols, because the polarities of these two eluents are not high enough to elute all the analytes. $\mathrm{MeOH}$ yielded the best recoveries among three alternative eluents (92-115\%) because this high polar protic solvent can elute the polar BPs more efficiently than less polar aprotic solvents (acetone and ethyl acetate). Consequently, methanol was chosen to elute all the BPs from HLB cartridges.

\subsection{Acidity of the samples}

During the quantitative extraction of phenolic compounds using SPE technique, the $\mathrm{pH}$ of the sample is usually considered as a key parameter and the effect has been fully studied [45-48]. Generally, the retention of phenolic compounds from water samples to reverse-phase SPE sorbents is owing to the nonpolar Van der Waals force between analytes and sorbents. Acidification of sample solution would keep the phenol compounds in molecular form and increase their affinity towards the sorbents [34]. Here, the effect of $\mathrm{pH}$ was also studied by adjusting the samples with hydrochloric acid. The results show that recoveries of analytes remain high and relatively similar at $\mathrm{pH}$ range from 2.5 to 6.3 (pure Milli-Q water), indicating not only reversed-phase mechanism but also $\pi-\pi$ interaction among electrons from aromatic ring in the sorbent and phenol molecules play roles in extraction process. In addition, the acidity of the samples affected the stabilities of BPs. In our preliminary studies, we found that BPs detected in the river water sample on the day of collection disappeared after 24-h storage in 


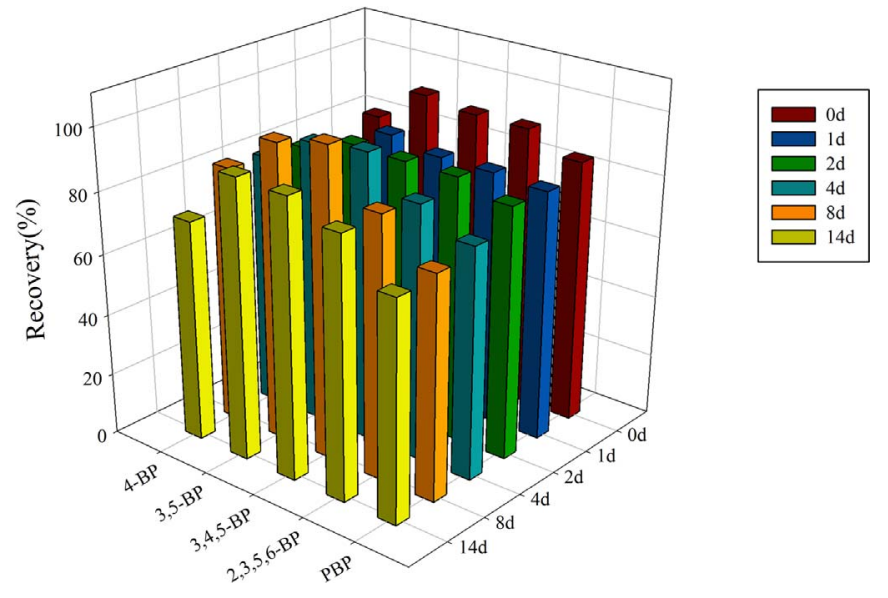

Fig. 4. The changes in the recoveries of five randomly selected BPs in the acidified water sample (pH 2.5).

the lab even at $4{ }^{\circ} \mathrm{C}$. Namely, inappropriate transportation and storage of the water samples led to the inaccurate determination of BPs. To ensure the stability of bromophenols, acidification would be necessary according to the sampling methods of other phenolic compounds. Considering that the pKa value of targeted BPs should be higher than the $\mathrm{pH}$ value of water samples, the acidification of water samples to $\mathrm{pH}$ 2.5 with hydrochloric acid would be necessary.

To examine the effects of acidity on the stability of various BPs, "blank river water" sample, in which the targeted compounds were not found, was acidified to $\mathrm{pH} 2.5$, spiked with BP standards, and stored at $4{ }^{\circ} \mathrm{C}$ without light. Then, the BPs were determined at different storage time points. In the pretreatment process, the SPE column loaded with water samples was firstly washed with $50 \mathrm{~mL}$ of ultrapure water to flush the hydrochloric acid off. The results showed that no significant diminution of the recoveries of BPs was found during two-week storage, meaning that the acidification of the samples effectively stabilized the targeted BPs. Fig. 4 shows the recovery-time curve of five BPs which was selected randomly to represent the same substituted bromophenols regarding bromine atom number. Therefore, the acidification of the samples to $\mathrm{pH} 2.5$ on site was performed for water sample collection avoiding the unnecessary degradation of the target compounds.

\subsection{Performance of the method}

The developed method was validated and evaluated in terms of linearity, sensitivity, spiking recovery and precision under the optimized condition, and the results were summarized in Table 2. Apparently, good linearity was obtained with the linear regression coefficient $\left(\mathrm{r}^{2}\right)$ higher than 0.998 when the concentrations of BPs ranged from 0.1 to $50 \mu \mathrm{g} / \mathrm{L}$. The behaviors of different BPs on LC-MS/ MS were significantly different. The equipment detection limits (EDLs) varied from 0.03 to $0.2 \mathrm{pg}$ for most of bromophenols. However, the detection sensitivities of 2,4,6-BP, 2,5-BP, and 2,4-BP are relatively low with the EDLs of $0.7,2.1$, and $2.4 \mathrm{pg}$, respectively. The sample matrix affected the determination to some extent. When compared to seawater samples, BPs in river water had lower method detection limits (MDLs) and better spiking recoveries. The MDLs of 2,4,6-BP and 2,4-BP in this study were close to the previously reported results based on GC/MS analysis $[11,19]$. While the MDL of pentabromophenol in this study was 10 folds lower than that of GC/MS method [11,27,28]. As for the other BPs which were not focused on in previous studies, high signal responses and low MDLs were obtained in this work. The high sensitivity of this method is helpful for the detection of trace amounts of BPs in aquatic system, which may provide the useful information on their environmental occurrence, distribution and fate. The average recoveries of all compounds ranged from $64 \%$ to $100 \%$. The precision of the method, expressed as the relative standard deviations (RSD, $\mathrm{n}=3$ ), were all less than $11 \%$. All parameters, including linearity, sensitivity, recovery and precision of the method, demonstrated that it was reliable and suitable for simultaneous analysis of various brominated phenols.

\subsection{Analysis of real samples}

The proposed method was applied to study the occurrence of BPs in various aqueous samples, including river water, swimming pool water, factory discharge wastewater and seawater (Table 3).

The wastewater sample discharged from a factory producing flame retardants contained relatively high concentrations of bromophenols, in which 2,4,6-TBP was dominant compound and its level was up to $7062.5 \mathrm{ng} / \mathrm{L}$. The concentration of 2,4,6-TBP exceeded its olfactory taste threshold $(600 \mathrm{ng} / \mathrm{L})$ with the characteristic earthy-musty odor $[49,50]$. Besides common BPs, such as 4-BP, 2,4-DBP and 2,4,6-TBP present in various environmental samples, 3-BP, 2,3-DBP and 3,5-DBP were also detected at a wide range of concentrations (2.6-1813.8 ng/ L). All the bromophenols in wastewater sample might be attributed to the industrial production, as the by-products of TBBPA and other brominated flame retardants which are the major products of the factory.

4-BP is generally considered as the natural product of marine algae instead of industrial material. However, 4-BP was detected in all the tested water samples. Its concentration was $44.9 \mathrm{ng} / \mathrm{L}$ in the river sample, which was relatively high because the sampling location was near a domestic sewage outlet. Considering the production of natural BPs rarely occur in fresh water, 4-BP detected in Qinghe River might originate from the anthropogenic input and the degradation of other widely used BFRs. As one of typical halogenated disinfection byproducts in chlorinated pool water, 4-BP was also confirmed at a very low concentration of $1.6 \mathrm{ng} / \mathrm{L}$ in a swimming pool, resulting from the interaction between residual chlorine in water and human body substances (such as urine) in the presence of bromide [51].

For seawater samples, 4-BP, 2,4-BP and 2,4,6-BP were detected from two coastal sites at different levels. In coastal seawater from Dalian, 2,4-BP and 2,4,6-BP were dominant with the concentrations of 27.5 and $26.2 \mathrm{ng} / \mathrm{L}$, respectively, which were comparable to the results achieved in German Bight (2-48 ng/L for 2,4-BP and n.d.-6 ng/L for 2,4,6-BP) and southeastern coastal areas of Korea (n.d.-32.7 ng/L for 2,4-BP and 0.38-20.2 ng/L for 2,4,6-BP) [11,52]. 2,4-BP and 2,6-BP were found in seawater from Tianjin with higher levels of 103.7 and $68.4 \mathrm{ng} / \mathrm{L}$, related to the different sampling locations and sources. 4-BP was detected from both sites at low levels in contrast to the findings in previous reports [11,52]. Besides the natural formation by marine biota, various anthropogenic sources affected the coastal areas. It is difficult to determine whether the compounds are biogenic or anthropogenic origin $[19,52]$.

\section{Conclusions}

A reliable and efficient analytical approach was developed and validated for the determination of bromophenols by SPE and LC-MS/ MS. It allows, for the first time, simultaneous analysis of 14 BPs with different substitutions in the environmental aqueous samples. The good linearity, sensitivity, recovery, and precision were validated for the newly-developed method, showing it was very promising in environmental analysis. The optimized method was finally applied to the determination of BPs in several kinds of water samples. Two monobromophenols, three di-bromophenols and 2,4,6-tribromophenol were found in the water samples. It was also found that BPs were not stable in the natural water system. The proposed method is practical and effective to investigate the occurrence and distribution of trace levels of BPs in diverse water matrixes. It was also helpful in exploration on the 
Table 2

The performance of the method. The linearity ranges for all BPs were from 0.1 to $50 \mu \mathrm{g} / \mathrm{L}$.

\begin{tabular}{|c|c|c|c|c|c|c|c|c|c|c|}
\hline \multirow[t]{2}{*}{ Compound } & \multicolumn{3}{|c|}{ Limits of detection } & \multirow{2}{*}{$\begin{array}{l}\text { Linear regression } \\
\text { coefficient }\left(\mathrm{r}^{2}\right)\end{array}$} & \multicolumn{3}{|c|}{ Spiking recovery (\%) } & \multicolumn{3}{|l|}{ RSD (\%) } \\
\hline & EDL (pg) & $\begin{array}{l}\text { MDL for } \\
\text { seawater (ng/ } \\
\text { L) }\end{array}$ & $\begin{array}{l}\text { MDL for } \\
\text { river water } \\
(\mathrm{ng} / \mathrm{L})\end{array}$ & & $\begin{array}{l}100 \mathrm{ng} / \mathrm{L} \text { in } \\
\text { seawater }\end{array}$ & $\begin{array}{l}1000 \mathrm{ng} / \mathrm{L} \text { in } \\
\text { seawater }\end{array}$ & $\begin{array}{l}150 \mathrm{ng} / \mathrm{L} \text { in } \\
\text { river water }\end{array}$ & $\begin{array}{l}100 \mathrm{ng} / \mathrm{L} \text { in } \\
\text { seawater }\end{array}$ & $\begin{array}{l}1000 \mathrm{ng} / \mathrm{L} \text { in } \\
\text { seawater }\end{array}$ & $\begin{array}{l}150 \mathrm{ng} / \mathrm{L} \text { in } \\
\text { river water }\end{array}$ \\
\hline 3-BP & 0.1 & 0.4 & 0.3 & 0.9995 & 70 & 71 & 88 & 3 & 6 & 3 \\
\hline 4-BP & 0.1 & 0.4 & 0.3 & 0.9996 & 66 & 71 & 82 & 2 & 2 & 3 \\
\hline 2,3-BP & 0.04 & 0.5 & 0.2 & 0.9997 & 91 & 91 & 96 & 3 & 5 & 2 \\
\hline 2,4-BP & 2.4 & 17.5 & $-\mathrm{b}$ & 0.9998 & 84 & 67 & $-{ }^{b}$ & 4 & 2 & $-{ }^{b}$ \\
\hline $2,5-\mathrm{BP}$ & 2.1 & 21.9 & 13.9 & 0.9986 & 73 & 64 & 76 & 1 & 2 & 11 \\
\hline $3,5-\mathrm{BP}$ & 0.03 & 0.5 & 0.2 & 0.9991 & 90 & 83 & 94 & 4 & 3 & 2 \\
\hline 2,3,4-BP & 0.2 & 0.8 & 0.7 & 0.9998 & 78 & 83 & 89 & 7 & 5 & 3 \\
\hline $2,4,5-\mathrm{BP}$ & 0.1 & 0.5 & 0.4 & 0.9999 & 75 & 83 & 93 & 5 & 7 & 5 \\
\hline $2,4,6-B P$ & 0.7 & 5.0 & 2.8 & 0.9999 & 75 & 71 & 87 & 1 & 2 & 5 \\
\hline $3,4,5-\mathrm{BP}$ & 0.03 & 0.1 & 0.1 & 0.9993 & 84 & 85 & 92 & 6 & 4 & 3 \\
\hline $2,3,4,5-\mathrm{BP}$ & 0.04 & 0.3 & 0.2 & 0.9997 & 84 & 90 & 100 & 5 & 10 & 8 \\
\hline $2,3,4,6-B P$ & 0.1 & 0.6 & 0.3 & 0.9994 & 83 & 87 & 92 & 3 & 2 & 0.4 \\
\hline $2,3,5,6-\mathrm{BP}$ & 0.1 & 1.0 & 0.5 & 0.9998 & 78 & 83 & 92 & 3 & 3 & 3 \\
\hline PBP & 0.1 & 0.3 & 0.3 & 0.9998 & 71 & 80 & 86 & 1 & 3 & 2 \\
\hline
\end{tabular}

${ }^{\mathrm{a}} \mathrm{n}=3$.

b Not detected.

Table 3

The concentrations of the target BPs detected in real water samples (ng/L).

\begin{tabular}{|c|c|c|c|c|c|c|}
\hline & 4-BP & 3-BP & 2,3-BP & 2,4-BP & $3,5-\mathrm{BP}$ & 2,4,6-BP \\
\hline River water & $44.9 \pm 0.8$ & n.d. ${ }^{a}$ & n.d. & n.d. & n.d. & n.d. \\
\hline Swimming pool water & $1.6 \pm 0.2$ & n.d. & n.d. & n.d. & n.d. & n.d. \\
\hline Factory discharge sewage & $675.0 \pm 35.6$ & $1813.8 \pm 35.9$ & $15.7 \pm 0.6$ & $1693.8 \pm 86.5$ & $2.6 \pm 0.2$ & $7062.5 \pm 335.1$ \\
\hline Bohai Seawater from Dalian & $3.1 \pm 0.2$ & n.d. & n.d. & $27.5 \pm 1.6$ & n.d. & $26.2 \pm 1.1$ \\
\hline Bohai Seawater from Tianjin & $5.0 \pm 0.8$ & n.d. & n.d. & $103.7 \pm 11.4$ & n.d. & $68.4 \pm 1.0$ \\
\hline
\end{tabular}

${ }^{\text {a }}$ Not-detectable.

environmental fate and transport process of BPs and other widely concerned compounds, like TBBPA and OH-PBDEs.

\section{Acknowledgements}

This work was jointly supported by the National Basic Research Program of China (2014CB441105), the National Natural Science Foundation of China (21277153) and Strategic Priority Research Program of the Chinese Academy of Sciences (XDB14010400).

\section{References}

[1] A. Covaci, S. Harrad, M.A.E. Abdallah, N. Ali, R.J. Law, D. Herzke, C.A. de Wit, Novel brominated flame retardants: a review of their analysis, environmental fate and behaviour, Environ. Int. 37 (2011) 532-556.

[2] World Health Organization, Flame retardants: a general introduction, Environmental health criteria no. 192, 1997. Available from 〈http://www.who.int/ iris/handle/10665/41961).

[3] World Health Organization, 2,4,6-Tribromophenol and other simple brominated phenols, Concise international chemical assessment document no. 66, 2005. Available from 〈http://www.who.int/iris/handle/10665/43228〉.

[4] J. Eriksson, S. Rahm, N. Green, Å. Bergman, E. Jakobsson, Photochemical transformations of tetrabromobisphenol A and related phenols in water, Chemosphere 54 (2004) 117-126.

[5] G. Grause, M. Furusawa, A. Okuwaki, T. Yoshioka, Pyrolysis of tetrabromobisphenol-A containing paper laminated printed circuit boards, Chemosphere 71 (2008) 872-878.

[6] O. Terakado, R. Ohhashi, M. Hirasawa, Thermal degradation study of tetrabromobisphenol A under the presence metal oxide: comparison of bromine fixation ability, J. Anal. Appl. Pyrol. 91 (2011) 303-309.

[7] H. Hakk, R.J. Letcher, Metabolism in the toxicokinetics and fate of brominated flame retardants-a review, Environ. Int. 29 (2003) 801-828.

[8] X.H. Qiu, R.M. Bigsby, R.A. Hites, Hydroxylated metabolites of polybrominated diphenyl ethers in human blood samples from the United States, Environ. Health Perspect. 117 (2009) 93-98.

[9] H.Y. Chung, W.C.J. Ma, P.O. Ang Jr., J.S. Kim, F. Chen, Seasonal variations of bromophenols in brown algae (Padina arborescens, Sargassum siliquastrum, and Lobophora variegata) collected in Hong Kong, J. Agric. Food Chem. 51 (2003)
2619-2624.

[10] F.B. Whitfield, M. Drew, F. Helidoniotis, D. Svoronos, Distribution of bromophenols in species of marine polychaetes and bryozoans from eastern Australia and the role of such animals in the flavor of edible ocean fish and prawns (shrimp), J. Agric Food Chem. 47 (1999) 4756-4762.

[11] W.J. Sim, S.H. Lee, I.S. Lee, S.D. Choi, J.E. Oh, Distribution and formation of chlorophenols and bromophenols in marine and riverine environments, Chemosphere 77 (2009) 552-558.

[12] K. Löfstrand, A. Malmvärn, P. Haglund, A. Bignert, Å. Bergman, L. Asplund, Brominated phenols, anisoles, and dioxins present in blue mussels from the Swedish coastline, Environ. Sci. Pollut. Res. 17 (2010) 1460-1468.

[13] F.B. Whitfield, F. Helidoniotis, K.J. Shaw, D. Svoronos, Distribution of bromophenols in species of ocean fish from eastern Australia, J. Agric. Food Chem. 46 (1998) 3750-3757.

[14] Y. Wan, S. Wiseman, H. Chang, X.W. Zhang, P.D. Jones, M. Hecker, K. Kannan, S. Tanabe, J.Y. Hu, M.H.W. Lam, J.P. Giesy, Origin of hydroxylated brominated diphenyl ethers: natural compounds or man-made flame retardants?, Environ. Sci. Technol. 43 (2009) 7536-7542.

[15] J. Deng, C.S. Liu, L.Q. Yu, B.S. Zhou, Chronic exposure to environmental levels of tribromophenol impairs zebrafish reproduction, Toxicol. Appl. Pharmacol. 243 (2010) 87-95.

[16] T. Hassenklöver, S. Predehl, J. Pilli, J. Ledwolorz, M. Assmann, U. Bickmeyer, Bromophenols, both present in marine organisms and in industrial flame retardants, disturb cellular $\mathrm{Ca}^{2+}$ signaling in neuroendocrine cells (PC12), Aquat. Toxicol. 76 (2006) 37-45.

[17] C.M. Olsen, E.T.M. Meussen-Elholm, J.A. Holme, J.K. Hongslo, Brominated phenols: characterization of estrogen-like activity in the human breast cancer cellline MCF-7, Toxicol. Lett. 129 (2002) 55-63.

[18] A.V. Lyubimov, V.V. Babin, A.I. Kartashov, Developmental neurotoxicity and immunotoxicity of 2,4,6-tribromophenol in Wistar rats, Neurotoxicology 19 (1998) 303-312.

[19] P. Lopez, S.A. Brandsma, P.E.G. Leonards, J. De Boer, Methods for the determination of phenolic brominated flame retardants, and by-products, formulation intermediates and decomposition products of brominated flame retardants in water, J. Chromatogr. A 1216 (2009) 334-345.

[20] Z.F. Ren, X.H. Bi, B. Huang, M. Liu, G.Y. Sheng, J.M. Fu, Hydroxylated PBDEs and brominated phenolic compounds in particulate matters emitted during recycling of waste printed circuit boards in a typical e-waste workshop of South China, Environ. Pollut. 177 (2013) 71-77.

[21] W. Han, S. Wang, H.L. Huang, L. Luo, S.Z. Zhang, Simultaneous determination of brominated phenols in soils, J. Environ. Sci. - China 25 (2013) 2306-2312.

[22] K. Öberg, K. Warman, T. Öberg, Distribution and levels of brominated flame 
retardants in sewage sludge, Chemosphere 48 (2002) 805-809.

[23] Y. Fujii, K.H. Harada, T. Hitomi, H. Kobayashi, A. Koizumi, K. Haraguchi, Temporal trend and age-dependent serum concentration of phenolic organohalogen contaminants in Japanese men during 1989-2010, Environ. Pollut. 185 (2014) $228-233$.

[24] D. Lankova, O. Lacina, J. Pulkrabova, J. Hajslova, The determination of perfluoroalkyl substances, brominated flame retardants and their metabolites in human breast milk and infant formula, Talanta 117 (2013) 318-325.

[25] X.H. Qiu, M. Mercado-Feliciano, R.M. Bigsby, R.A. Hites, Measurement of polybrominated diphenyl ethers and metabolites in mouse plasma after exposure to a commercial pentabromodiphenyl ether mixture, Environ. Health Perspect. (2007) 1052-1058.

[26] K.D. Lin, J. Gan, W.P. Liu, Production of hydroxylated polybrominated diphenyl ethers from bromophenols by bromoperoxidase-catalyzed dimerization, Environ. Sci. Technol. 48 (2014) 11977-11983.

[27] J.B. Quintana, R. Rodil, S. Muniategui-Lorenzo, P. López-Mahía, D. PradaRodríguez, Multiresidue analysis of acidic and polar organic contaminants in water samples by stir-bar sorptive extraction-liquid desorption-gas chromatographymass spectrometry, J. Chromatogr. A 1174 (2007) 27-39.

[28] M. Polo, M. Llompart, C. Garcia-Jares, G. Gomez-Noya, M.H. Bollain, R. Cela, Development of a solid-phase microextraction method for the analysis of phenolic flame retardants in water samples, J. Chromatogr. A 1124 (2006) 11-21.

[29] H. Chang, Y. Wan, J. Naile, X.W. Zhang, S. Wiseman, M. Hecker, M.H.W. Lam, J.P. Giesy, P.D. Jones, Simultaneous quantification of multiple classes of phenolic compounds in blood plasma by liquid chromatography-electrospray tandem mass spectrometry, J. Chromatogr. A 1217 (2010) 506-513.

[30] D. Lankova, M. Kockovska, O. Lacina, K. Kalachova, J. Pulkrabova, J. Hajslova, Rapid and simple method for determination of hexabromocyclododecanes and other LC-MS-MS-amenable brominated flame retardants in fish, Anal. Bioanal. Chem. 405 (2013) 7829-7839.

[31] C. Feng, Q. Xu, Y.E. Jin, Y.J. Lin, X.L. Qiu, D.S. Lu, G.Q. Wang, Determination of urinary bromophenols (BrPs) as potential biomarkers for human exposure to polybrominated diphenyl ethers (PBDEs) using gas chromatography-tandem mass spectrometry (GC-MS/MS), J. Chromatogr. B 1022 (2016) 70-74.

[32] EU Commission Decision 2002/657/EC, Commission Decision of 12 August 2002 implementing Council Directive 96/23/EC concerning the performance of analytical methods and the interpretation of results, Official Journal no. L 221, 2002.

[33] H. Kuramochi, K. Maeda, K. Kawamoto, Water solubility and partitioning behavior of brominated phenols, Environ. Toxicol. Chem. 23 (2004) 1386-1393.

[34] I. Rodríguez, M.P. Llompart, R. Cela, Solid-phase extraction of phenols, J. Chromatogr. A 885 (2000) 291-304.

[35] N.C. Dias, C.F. Poole, Mechanistic study of the sorption properties of Oasis ${ }^{\circledR}$ HLB and its use in solid-phase extraction, Chromatographia 56 (2002) 269-275.

[36] M.C. Jin, X.H. Chen, B.X. Pan, Simultaneous determination of 19 chlorophenols in water by liquid chromatography-mass spectrometry with solid-phase extraction, J. Liq. Chromatogr. Relat. Technol. 29 (2006) 1369-1380.

[37] S. Insa, V. Salvadó, E. Anticó, Development of solid-phase extraction and solidphase microextraction methods for the determination of chlorophenols in cork macerate and wine samples, J. Chromatogr. A 1047 (2004) 15-20.
[38] J.L. Martínez Vidal, A. Belmonte Vega, A. Garrido Frenich, F.J. Egea González, F.J. Arrebola Liebanas, Determination of fifteen priority phenolic compounds in environmental samples from Andalusia (Spain) by liquid chromatography-mass spectrometry, Anal. Bioanal. Chem. 379 (2004) 125-130.

[39] A. Martínez-Uruñuela, I. Rodríguez, R. Cela, J.M. González-Sáiz, C. Pizarro, Development of a solid-phase extraction method for the simultaneous determination of chloroanisoles and chlorophenols in red wine using gas chromatographytandem mass spectrometry, Anal. Chim. Acta 549 (2005) 117-123.

[40] P. Canosa, S. Morales, I. Rodríguez, E. Rubí, R. Cela, M. Gómez, Aquatic degradation of triclosan and formation of toxic chlorophenols in presence of low concentrations of free chlorine, Anal. Bioanal. Chem. 383 (2005) 1119-1126.

[41] R. Liu, J.L. Zhou, A. Wilding, Simultaneous determination of endocrine disrupting phenolic compounds and steroids in water by solid-phase extraction-gas chromatography-mass spectrometry, J. Chromatogr. A 1022 (2004) 179-189.

[42] L.R. Snyder, Classification of the solvent properties of common liquids, J. Chromatogr. A 92 (1974) 223-230.

[43] M. Markom, M. Hasan, W.R.W. Daud, H. Singh, J.M. Jahim, Extraction of hydrolysable tannins from Phyllanthus niruri Linn.: effects of solvents and extraction methods, Sep. Purif. Technol. 52 (2007) 487-496.

[44] K. Bielicka-Daszkiewicz, A. Voelkel, M. Szejner, J. Osypiuk, Extraction properties of new polymeric sorbents in SPE/GC analysis of phenol and hydroquinone from water samples, Chemosphere 62 (2006) 890-898.

[45] N. Fattahi, S. Samadi, Y. Assadi, M.R.M. Hosseini, Solid-phase extraction combined with dispersive liquid-liquid microextraction-ultra preconcentration of chlorophenols in aqueous samples, J. Chromatogr. A 1169 (2007) 63-69.

[46] L. Elci, N. Kolbe, S.G. Elci, J.T. Anderson, Solid phase extractive preconcentration coupled to gas chromatography-atomic emission detection for the determination of chlorophenols in water samples, Talanta 85 (2011) 551-555.

[47] X.S. Li, L.D. Xu, Y.B. Shan, B.F. Yuan, Y.Q. Feng, Preparation of magnetic poly (diethyl vinylphosphonate-co-ethylene glycol dimethacrylate) for the determination of chlorophenols in water samples, J. Chromatogr. A 1265 (2012) 24-30.

[48] H. Bagheri, M. Saraji, Conductive polymers as new media for solid-phase extraction: isolation of chlorophenols from water sample, J. Chromatogr. A 986 (2003) 111-119.

[49] J.L. Acero, P. Piriou, U, von Gunten, Kinetics and mechanisms of formation of bromophenols during drinking water chlorination: assessment of taste and odor development, Water Res. 39 (2005) 2979-2993.

[50] F.B. Whitfield, J.H. Last, K.J. Shaw, C.R. Tindale, 2,6-Dibromophenol: the cause of an iodoform-like off-flavour in some Australian crustacea, J. Sci. Food Agric. 46 (1988) 29-42.

[51] F. Xiao, X.R. Zhang, H.Y. Zhai, I.M.C. Lo, G.L. Tipoe, M.T. Yang, Y. Pan, G.H. Chen, New halogenated disinfection byproducts in swimming pool water and their permeability across skin, Environ. Sci. Technol. 46 (2012) 7112-7119.

[52] N. Reineke, S. Biselli, S. Franke, W. Francke, N. Heinzel, H. Hühnerfuss, H. Iznaguen, U. Kammann, N. Theobald, M. Vobach, W. Wosniok, Brominated indoles and phenols in marine sediment and water extracts from the north and baltic seas-concentrations and effects, Arch. Environ. Contam. Toxicol. 51 (2006) 186-196. 